\title{
Haemodynamic measurements prior to ventricular fibrillation or asystole following experimental coronary occlusion ${ }^{1}$
}

\author{
ERIK BERGLUND, LEON RESNEKOV?, \\ GÖRAN WILLIAM-OLSSON, AND ANN-CHRISTINE ÖHRLUND \\ From the Thoracic Surgery Research Laboratory, Karolinska Siukhuset, 10401 Stockholm 60, Sweden
}

Dogs under general anaesthesia were studied following occlusion of a branch of the left circumflex artery produced by wedging a radio-opaque catheter under fluoroscopic control. In two dogs an aluminium-coated steel needle was lodged in place via the catheter. Pressures in the left atrium, left ventricle, pulmonary artery, and right atrium were recorded in nine dogs following this procedure, and in two of these serial cardiac outputs were determined. In four dogs the fatal dysrhythmia was preceded by bursts of ventricular rhythm disturbances without evidence of heart failure, and in one dog sudden fatal ventricular tachycardia occurred without any preceding warning. Flow measurements in one of these dogs showed no fall in output or stroke volume. In two dogs the left ventricular filling pressure gradually rose before the development of ventricular fibrillation. No change in output or stroke volume was shown in one of these dogs. Two dogs developed increasing ventricular irritability together with evidence of left ventricular failure, and in one dog, who was resuscitated from ventricular fibrillation, left ventricular failure leading to death occurred later the same day. Right atrial pressure was shown to be a misleading index of myocardial function, and the only evidence for impending acute circulatory embarrassment was increasing ventricular irritability.

Mortality following myocardial infarction has been considerably reduced with the advent of the Coronary Care Unit. In the main, this reflects considerable success in the prevention, recognition, and treatment of acute rhythm disturbances; failure of the heart as a pump remains a therapeutic challenge. Monitoring of various haemodynamic parameters, particularly central venous pressure, may be disappointing as a warning of impending acute circulatory embarrassment. The present investigation was undertaken to determine which haemodynamic parameter would best serve as a warning of impending death following the production of acute myocardial infarction in experimental animals.

\section{MATERIAL AND METHODS}

Twelve mongrel dogs were studied under intravenous anaesthesia induced and maintained with sodium pentobarbital. The trachea was intubated with a

1With support from the Swedish Medical Research Council and the Swedish National Association against Heart and Lung Diseases ${ }^{2}$ In receipt of a Wellcome Foundation Research Grant cuffed tube, and the dogs were allowed to breathe spontaneously; from time to time the lungs were forcefully inflated to prevent collapse.

Cardiac catheters were introduced via skin in cisions: one was advanced from the jugular veib trans-septally into the left atrium, one was positioned in the right atrium, and one in the pulmonary artery In one dog the left ventricle was catheterized in retrograde fashion from the femoral artery. Af catheter positioning was undertaken under fluoros scopic control, and the position of the catheters was checked by observing the pressure tracings and bloo gas saturations. Pressures were recorded with reference to the level of the right atrium, using electrical trans ducers (Elema). Extremity electrocardiographic leadsu were recorded together with pressures on an ink-ję oscillograph (Elema).

In two of the dogs, serial cardiac outputs were determined repeatedly at one-minute intervals. Cardio green was injected into the pulmonary artery an blood was withdrawn from the aorta through $a$ Waters' densitometer. Serial blood dilution curveș were obtained for calibration.

Following the collection of control data, occlusio市 of the left circumflex coronary artery was produce $\mathbb{B}$ either by wedging a radio-opaque Ödman Teflo을 
catheter in the artery or by lodging an aluminiumcoated steel needle in the artery via a radio-opaque catheter.

\section{RESULTS}

A relatively large area of the coronary supply was occluded so that arrest or fibrillation might occur in a relatively short space of time. Nine dogs survived occlusion of the left circumflex artery long enough for the haemodynamic measurements to be made. The duration between the occlusive procedure and death varied from 3 to 36 minutes. Once the occlusion had occurred, all haemodynamic and electrocardiographic records were monitored continuously. In the analysis, particular attention was directed to the last few minutes before ventricular fibrillation or asystole supervened. The pertinent data are shown in the Table. The following patterns were found:

1. DYSRHYTHMIA WITHOUT EVIDENCE OF MYOCARDIAL FAILURE Five dogs had 'primary dysrhythmia'. Ventricular fibrillation was preceded by occasional ventricular extrasystoles or by frequent extrasystoles; in dog 966, the terminal ventricular dysrhythmia was preceded by a burst of ventricular tachycardia. In $\operatorname{dog} 678$, no preceding dysrhythmia occurred, and ventricular fibrillation occurred without any preceding warning.

The cardiac output was measured in dog 100 ; the cardiac output increased from 2.5 to 3.51 ./ min. and the stroke volume increased from 15 to $25 \mathrm{ml}$. during the last 3 minutes prior to the development of ventricular extrasystoles leading to ventricular fibrillation.
2. MYCCARDIAL FAILURE WITH GRADUALLY INCREASING LEFT ATRIAL AND END-DIASTOLIC PRESSURE IN THE LEFT VENTRICLE This course occurred in two dogs (921 and 70). Left ventricular diastolic pressure rose in dog 70 from 3 to $32 \mathrm{~mm} \mathrm{Hg}$, and in $\operatorname{dog} 921$ from 0 to $9 \mathrm{~mm}$. $\mathrm{Hg}$. In $\operatorname{dog} 921$, the cardiac output was repeatedly determined, but no definite change in stroke volume or cardiac output was measured. Dog 750 , originally referred to under group 3 (below), who initially developed combined dysrhythmia and myocardial failure, gradually developed left ventricular failure following resuscitation and died the same evening.

3. COMBINED DYSRHYTHMIA AND MYOCARDIAL FAILURE This pattern occurred in two dogs. In dog 646 the dysrhythmia began with single ventricular ectopic beats and ultimately ventricular tachycardia, and then fibrillation supervened. Myocardial failure was evidenced by an increase in left atrial pressure from 3 to $30 \mathrm{~mm}$. $\mathrm{Hg}$, which preceded the terminal dysrhythmia by 5 minutes and was associated with a fall in aortic systolic pressure from 125 to $42 \mathrm{~mm}$. $\mathrm{Hg}$. In dog 750, left atrial pressure rose and arterial pressure fell slightly during the last 2 minutes before fibrillation, and there were a few ectopic beats. The dog was swiftly resuscitated by artificial ventilation and external cardiac massage and later developed the pattern described under group 2 above.

Evidence for right heart failure was always less than for left heart failure, and the right atrial pressure frequently failed to reflect any increase in left atrial or left ventricular end-diastolic pressure. For example, in dog 70 when the left ventricular end-diastolic pressure rose from 3 to 32

T A B L E

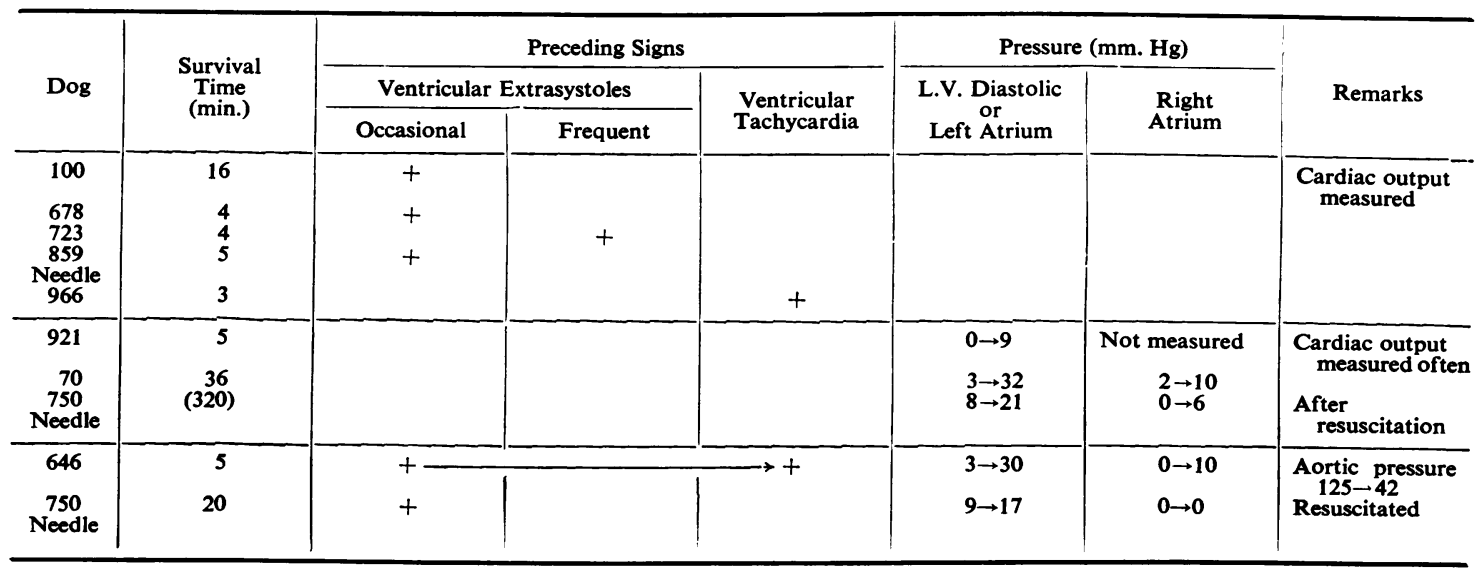


$\mathrm{mm} . \mathrm{Hg}$, the right atrial pressure rose only from 2 to $10 \mathrm{~mm}$. $\mathrm{Hg}$. In dog 646, right atrial pressure rose from 0 to $10 \mathrm{~mm}$. $\mathrm{Hg}$. at a time when the left atrial pressure rose from 3 to $30 \mathrm{~mm}$. $\mathrm{Hg}$. Similarly, profound changes in heart rate failed to occur with the onset of myocardial dysfunction.

As was to be expected, the electrocardiogram showed QRS-T segment and T-wave changes typical of acute myocardial infarction apart from any dysrhythmia, but the shape or degree of change bore no relation to the imminence of haemodynamic changes or of impending death.

\section{DISCUSSION}

A satisfactory animal model for studying haemodynamic events following acute coronary insufficiency is difficult to achieve. We wanted to produce myocardial ischaemia without using thoracotomy. Here we wedged a catheter in the circumflex artery beyond the point of origin of the anterior descending artery, creating ischaemia in the lateral part of the left ventricle, or placed a needle in the left circumflex coronary artery (William-Olsson, Otoya, and Berglund, 1969).

No single consistent pattern followed the creation of experimental myocardial infarction. Primary dysrhythmia was the most common as is the case in man (Lawrie, Greenwood, Goddard, Harvey, Donald, Julian, and Oliver, 1967). Ventricular filling pressure, cardiac output, and stroke volume determinations were of little help in judg- ing the imminence of ventricular fibrillation asystole in six of the nine dogs studied. Whe left ventricular failure did precede terminal ve tricular fibrillation, end-diastolic pressure in the left ventricle and the mean left atrial pressure ro far higher than did pressure in the right atrium The central venous pressure is, if anything, mis. leading where isolated left ventricular failu $\overrightarrow{\mathrm{EB}}$ develops. This is in agreement with studies dor? on open-chested dogs (Berglund, 1954).

The primary rhythm disturbance which followed occlusive constriction of a smallep branch of the coronary arterial tree was presums ably due to local diminution of threshold for fibrillation, as shown experimentally by Shumwa $\bar{y}$, Johnson, and Stish (1957), and differs from the events which follow constriction of the main le coronary artery (Case, Berglund, and Sarno 1954).

\section{REFERENCES}

Berglund, E. (1954). Ventricular function. VI. Balance of left and rigeg ventricular output: relation between left and right atrial pressures. Amer.J. Physiol., 178, 381.

Case, R. B., Berglund, E., and Sarnoff, S. J. (1954). Ventricular fure tion. II. Quantitative relationship between coronary flow a ventricular function with observations on unilateral failuz Circulat. Res., 2, 319.

Lawrie, D. M., Greenwood, T. W., Goddard, M., Harvey, A. है Donald, K. W., Julian, D. G., and Oliver, M. F. (1967). CQ coronary-care unit in the routine management of acute myocardia infarction. Lancet, 2, 109.

Shumway, N. E., Johnson, J. A., and Stish, R. J. (1957). The study ventricular fibrillation by threshold determinations. J. thorad Surg., 34, 643.

William-Olsson, G., Otoya, E., and Berglund, E. (1969). Producti $\bar{P}$ of coronary insufficiency in the dog without thoracotomy. $F$ preparation. 